\title{
PROCESOS DE PARTICIPACIÓN Y DEMOCRATIZACIÓN DE LA FACULTAD DE EDUCACIÓN
}

\author{
OFELIA RAMÍREZ \\ HERNANDO GUTIÉRREZ *
}

En el año de 1991 se intentó en nuestro país un pacto social con el fin de modernizar el Estado y adecuarlo a las expectativas de una nueva sociedad dentro de la cual se le diera mayor participación a sus miembros en la formulación de las políticas que lo rigen, al igual que garantizar una acción permanente de control y fiscalización de los diferentes procesos que se adelanten a través de los múltiples organismos que lo conforman y, tal vez lo más importante, dejar abierta la posibilidad de reformarlo y/o reestructurarlo.

Todo este esfuerzo se orientaba a buscar un ambiente propicio para la convivencia pacífica dentro de un Estado que garantizara, a través de la racionalidad de sus instituciones jurídico-políticas, la equilibración de las relaciones sociales entre sus miembros y propiciara mecanismos para unas condiciones materiales de existencia dignas de seres humanos.

Se trataba entonces de demucratizar todos los procesos que tienen que ver con el manejo del Estado en el sentido de procurar la participación real y efectiva de todos los asociados comprometidos directamente en esos procesos.

Se aspiraba a pasar de la democracia representativa, que no dejaba de ser un sim-

- Profesores de la Universidad Surcolombiana. ple embeleco para encubrir o mitigar las más aberrantes injusticias y las más odiosas discriminaciones, a la democracia participativa entendida esta como la manifestación directa de la voluntad de los ciudadanos a través de mecanismos expeditos que faciliten y garanticen la expresión generalizada y el respeto al libre albedrío.

Dado que la escogencia de sus gobernantes es una de las manifestaciones primarias y fundamentales de la democracia, se amplió la cobertura de funcionarios de la rama ejecutiva del poder público que debían, y podrían, seleccionarse mediante la consulta popular directa. Igualmente, se establecieron mecanismos de participación ciudadana en consonancia con los propósitos de hacer efectivas las aspiraciones de involucrar, directamente, a los asociados en la elaboración y fiscalización de las políticas del Estado. La consulta popular, el referendo, el plebiscito, el cabildo abierto y la revocatoria de mandato, etc., fueron los principales instrumentos puestos a disposición de los ciudadanos como mecanismos de participación.

Desafortunadamente, siete años después de este pretendido revolcón no hemos podido avanzar del carnaval electoral al cual finalmente vino a quedar reducida la intencionalidad democratizadora de la Constituyente del año 91. Resulta frustrante que ningún otro mecanismo de participación demo- 
crática haya podido ser realmente aplicado en nuestro país cuando ha habido motivos suficientes para ello. Ni revocatorias de mandato, ni consultas populares, ni referendos, etc., han podido ser adelantados. Continuamos pues con una democracia formal, de papel; manipulada por los prestidigitadores y maniqueos de siempre que, hasta ahora, han sido los más beneficiados, pues, multiplicaron los espacios para extender sus mercados de votos.

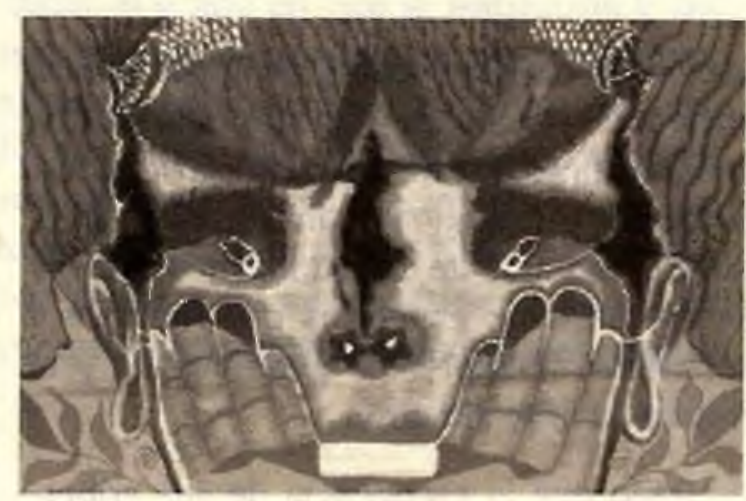

Ilustración: Morera C.

La corrupción administrativa, habitual en las diferentes dependencias de la administración pública, que se pretendía erradicar mediante las veedurías ciudadanas, se ha incrementado. Los dineros públicos se desvían a las cuentas personales de los funcionarios que participan en asignación de contratos y en la compra de implementos para funcionamiento.

El Estado se ha debilitado notoriamente en sus propósitos fundamentales a saber:

La asistencia social y la protección de sus asociados. Respecto a lo primero, se enfatizan los procesos de privatización, disfrazados con el discurso de la productividad, la cofinanciación y la responsabilidad compartida, en salud y educación. En cuanto a lo segundo, la desprotección física, se dejó a los ciudadanos en la intemperie; la asistencia y el control judicial que debe mediar en los conflictos sociales se dejó en manos de la justicia privada y el paramilitarismo.
El desempleo, el hambre y la carencia de oportunidades para abrazar un futuro esperanzador han generado la dispersión, el abandono y un terrible grito de "sálvese quien pueda" que acalló los ímpetus de ejercer la democracia plena nacida de un pacto social a medias que no concitó la voluntad de todos los sectores que de una u otra forma se vienen manifestando para construir Patria.

Valdría la pena, y así está inscrito en los propósitos de este evento, reflexionar sobre el papel que ha jugado la Universidad y en particular la facultad de Educación dentro de este proceso generado a partir de la Constitución de 1991.

Pareciera que nos hubiésemos engolosinado con la dádiva democratera que nos permite escoger nuestras directivas universitarias, y una autonomía de juguete que sólo sirve para golpear las pocas voces de protesta que aún se manifiestan en su interior pero que no sirve, no funciona, frente a las agresiones del propio Estado.

No ha trascendido el concepto de democracia más allá de la simple participación electoral o del dominio de "la mitad más uno" o la agresiva dictadura de "mayoría manda".

Nos negamos durante siete años la posibilidad, y más aún la necesidad, de indagar sobre el concepto de democracia, sus potencialidades e incluso de inventar y experimentar formas de convivencia y bienestar social que permitieran su enriquecimiento.

El ejercicio de la democracia dentro de la Universidad y en nuestra Facultad se ha limitado a la escogencia, mediante procesos electorales paradógicamente antidemocráticos, de algunos cargos directivos.

Hoy, que nuevamente nuestro país intenta talvez la última oportunidad de un pacto social que nos permita de manera pacífica y civilizada conciliar nuestras diferencias para 
superar los desequilibrios sociales y económicos y procurarnos mejores condiciones de vida, debemos interrogarnos sobre ¿qué hacer para que nuestra Universidad y particularmente la Facultad de Educación se integren a los procesos de democratización que se adelantan a nivel de la sociedad en general, con miras al proceso de construcción del nuevo país.

¿Qué hacer para que en nuestra facultad de Educación se democraticen los diferentes procesos que a ella le competen y, a su vez, se implementen mecanismos que garanticen la participación de los profesores, estudiantes y la comunidad educativa en general en estos procesos?

¿Qué papel puede y debe jugar la facultad de Educación en el cultivo, difusión y ejercitación, entre su comunidad educativa, de los principios y valores democráticos?

Sin pretender sentar cátedra sobre el particular, presentamos algunas inquietudes que consideramos deben tenerse en cuenta para responder positivamente a los interrogantes anteriores.

En primer lugar tenemos que intentar una aproximación al concepto moderno (y por qué no, postmoderno) de democracia que supere los estrechos marcos de "la mayoría" representada en "la mitad más uno"; que tenga en cuenta el respeto por las minorías; el reconocimiento y respeto por la diferencia, la unidad en la diversidad, etc.

Esta prioritaria tarea la podemos abordar a través de talleres asistidos por profesores especializados de los que se encuentran vinculados a las maestrías del CINDE y la Nacional en convenio con la USCO.

Viene luego una sincera reflexión personal (que seguramente puede resultar tardía por lo avanzado de nuestra edad y estar adportas de la jubilación) que le permita a cada cual tomar decisiones con respecto al gra- do de compromiso que asuma en relación con su participación en esta empresa.

La democracia no puede quedarse al nivel teórico de categoría intelectual; es necesario vivenciarla, confrontarla en la actividad práctica. En tal sentido, si nos comprometemos en esta empresa, debemos incluirla en nuestro proyecto personal tanto en su componente ética como política. No podemos seguir convirtiendo la democracia en letra muerta. De nada sirve disponer de estatutos, reglamentos, programas académicos, diseños curriculares y proyectos educativos institucionales en los cuales se exalte de manera apologética la democracia si nuestra práctica cotidiana está determinada por la despreocupación, la dejadez, la indiferencia, la insolidaridad y el egocentrismo. Si no hay compromiso colectivo; si no hay unos objetivos e intereses comunes que nos identifiquen y aglutinen en torno a esta empresa; si no hay un norte hacia donde ir, no tiene sentido que nos engañemos ni que engañemos la comunidad.

El reto del momento es la integración de la facultad de Educación al proceso de reestructuración político-social y económica con el cual la denominada sociedad civil (otro concepto que debemos abordar y profundizar), el gobierno y los grupos rebeldes alzados en armas pretenden un nuevo pacto social para lograr la paz y construir una nueva sociedad menos hostil y más agradable para vivir.

Cualqquier proceso de reestructuración que intente la facultad debe inscribirse dentro de este proceso pues de lo contrario podríamos correr el riesgo de quedar por fuera de la nueva Colombia que se propone. $\mathrm{Al}$ igual que en el primer punto, debemos, desde ya, adelantar foros, talleres y seminarios que nos coloquen a tono con el debate que se adelanta en el país en el marco de los diálogos de paz y las consecuentes transformaciones sociales, políticas y económi- 
cas que se propongan como requisitos para la convivencia pacífica.

Finalmente, debemos avanzar en el proceso de consolidación y ejercicio de la au-

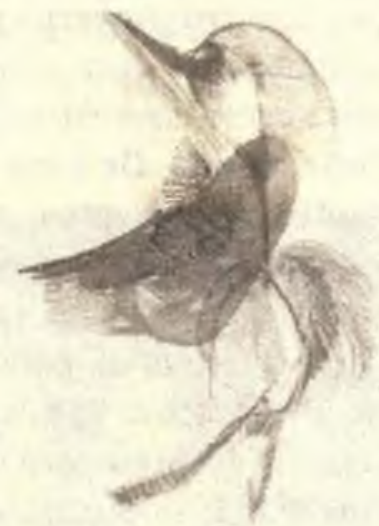

llustración: Maribel Castro tonomía e independencia de la facultad con respecto a la dirección central de la Universidad, para evitar que los procesos de democratización que intentemos sean bloqueados.

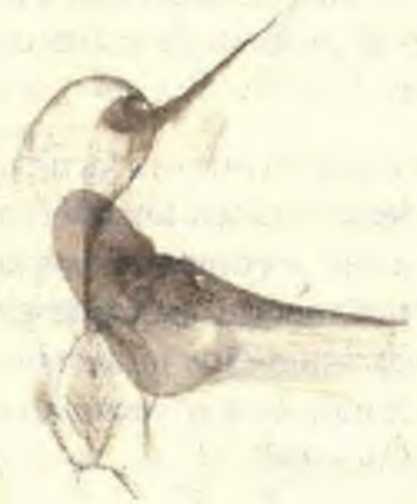

